\title{
Non-linear interaction between tidal and subinertial barotropic flows in the Strait of Gibraltar
}

Barotropic flow Subinertial flow Tide in channel Non-linear interaction Strait of Gibraltar

Flux barotrope Flux subinertiel Marée dans un canal Interaction non linéaire Détroit de Gibraltar

Rafael MAÑANES, M. BRUNO, J. ALONSO, B. FRAGUELA and L. TEJEDOR

Facultad de Ciencias del Mar. Polígono del Río San Pedro S/n. Apartado 40. Puerto Real. Cádiz, Spain.

Received 17/12/96, in revised form 01/04/97, accepted 30/04/97.

\section{ABSTRACT}

The present work establishes clear relationships of the amplitude and phase variation of the barotropic $M_{2}$ signal in the velocity of the current with the barotropic subinertial flow in the Strait of Gibraltar. The analytical procedure is applied on data from Gibraltar Expcriment in order to obtain barotropic subinertial series and the amplitude and phase variation of the $M_{2}$ signal series involves harmonic analysis, empirical orthogonal function analysis and complex demodulation. In addition, cross-spectral analysis has been applied to study these relationships, concerning which non-linear interaction between $M_{2}$ and the subinertial oscillation is proposed as the responsible physical mechanism. An analytical solution characterizing this type of non-linear interaction is offered in explanation of the experimental results. (C) Elsevier, Paris.

\section{RÉSUMÉ \\ RESUME}

Interaction non linéaire entre les flux barotropes de marée et subinerticl dans le détroit de Gibraltar.

\begin{abstract}
Le présent travail établit les relations entre l'amplitude et les variations de phase du signal barotrope $M_{2}$ dans le détroit de Gibraltar et le flux barotrope subinertiel. Les séries de données sont traitées par un ensemble de méthodes : analyse harmonique, analyse des fonctions orthogonales empiriques, démodulation complexe et analyse spectrale croisée. Le mécanisme physique responsable des relations entre le signal $M_{2}$ et l'oscillation subinertielle est l'interaction non linéaire. Une solution analytique de ce type d'interaction explique des résultats expérimentaux. (C) Elsevier, Paris.
\end{abstract}

Oceanologica Acta, 1998, 21, 1, 33-46.

\section{INTRODUCTION}

From the oceanographic point of view, the Strait of Gibraltar is known to play an important role in controlling the exchange of water masses between the Mediterranean Sea and the Atlantic Ocean. On a stationary scale, the responsible mechanisms for moving these water masses are the density and mean sea level differences between both basins mainly. Over this stationary structure, other water mass movements with different temporal variability scales are found. According to their temporal scales the flows in the Strait of Gibraltar can be classified (Lacombe and Richez, 1982) as: long-period, subinertial and tidal.

The forcing mechanism of subinertial flows has been investigated by different authors and related to atmospheric 
pressure fluctuations over the Mediterranean Sea (Crepon, 1965; Garrett, 1983; García, 1986; Candela, 1989; Candela et al., 1989). Estimated low-frequency variability transports are 0.37 and $0.22 \mathrm{~Sv}$ for Atlantic inflow and Mediterranean outflow respectively (Bryden et al., 1994).

The tidal flow in the Strait is the result of the coupling between the Atlantic and Mediterranean tidal regimes (García, 1986; Candela, 1989; Ruíz, 1994). The estimated tidal transports are 2.3 and $1.3 \mathrm{~Sv}$ for inflow and outflow respectively (Bryden et al., 1994).

The tidal and subinertial flows can be considered almost unidirectional, with a clear predominance of the west-east component of the current velocity " $u$ " over the south-north component " $v$ " (Pillsbury et al., 1987).

An important feature of the tidal and subinertial flows is that they can be considered, as a first approach, as barotropic, i.e. depth-independent. Candela (1989) and Ruíz (1994) have found that 93 and $84 \%$, respectively, of the variance of current velocities in semidiurnal and subinertial bands have a barotropic character in the Strait of Gibraltar. The $M_{2}$ signal explains over $64 \%$ of the tidal barotropic flow variance (Candela, 1989; Candela et al., 1990) and can therefore be used to characterize a very important part of the tidal phenomenon in the Strait.

One of the pending subjects of oceanographic studies in the Strait of Gibraltar is the analysis of non-linear phenomena affecting tidal and subinertial oscillations. Several authors have studied this problem in connection with sea elevation records taken along the Strait (García, 1986; Garrett et al., 1989; Mañanes et al., 1995). The present work establishes clear relationships of the amplitude and phase-lag variation of the barotropic $M_{2}$ signal in the velocity of the current with the barotropic subinertial current in the Strait of Gibraltar. These relationships will be explained, taking as a basis the non linear interactions between $M_{2}$ and the subinertial signals in the current velocity.

The organization of the paper is as follows. The first part describes data records and their processing in order to obtain the barotropic subinertial oscillation mode and the amplitude and phase variation of the $M_{2}$ barotropic signal. In the second part, the relationship between the series alrcady described is established and discussed. The third part is devoted to semidiurnal residues and their spatial variations along the Strait. In the fourth part, the nonlinear interaction between $M_{2}$ and subinertial oscillation is proposed as the physical mechanism responsible for the generation of the semidiurnal residues. A quasi-analytical solution characterizing this kind of non-linear interaction is used to explain the experimental results. In the fifth and final part, the comparison between the observed and theoretical results is discussed.

\section{DATA AND METHODOLOGY}

Current velocity data were obtained from the Gibraltar Experiment (1985--1986). Not all the moorings available in this experiment were used, but only those which met the following conditions: they must be located close to the longitudinal axis of the Strait, and be well separated from

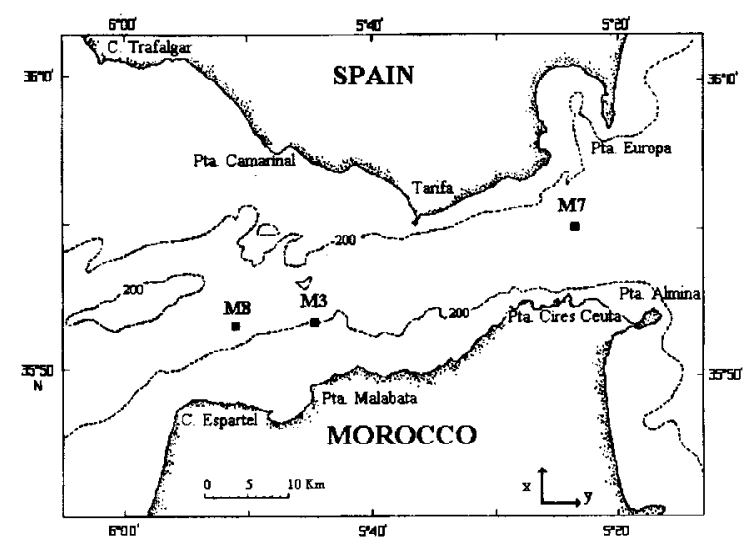

a)

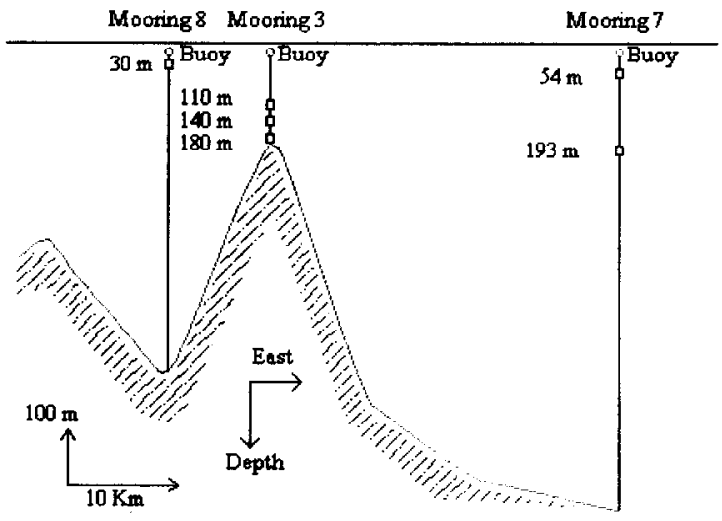

b)

Figure 1

a) Map of the studied zone, with the location of the selected moorings $M 8, M 3$ and $M 7 ; b)$ detail of the selected moorings.

each other; and they must be the subject of the longest simultaneous period of recordings. On the basis of these criteria, moorings M8, M3 and M7 were selected (Fig. 1a). The longest simultaneous record comprised about three months of hourly data (Table 1).

The purpose now is to determine the series which represent, on the one hand, the barotropic subinertial signal and, on the other hand, the amplitude and phase variations of the barotropic $M_{2}$ signal in the velocity data of the current. It will be found that the barotropic subinertial signal can be represented by a common oscillation mode along the entire Strait which will be characterized by its temporal weight $M_{1}(t)$. After the distorted $M_{2}$ signal is obtained, the slow variations in time of the amplitude and phase of the $M_{2}$ signal are computed by the application of complex demodulation to the distorted $M_{2}$ signal. These slow variations in time of amplitude and phase have been called $U_{m}(t)$ and $\phi_{m}(t)$, respectively, and are determined together with $M_{1}(t)$, for use in the next section to analyse the relationship of $M_{1}(t)$ with $U_{m}(t)$ and $\phi_{m}(t)$. 
Table 1

Information concerning the moorings M3, M8 and M7 used in the present work.

\begin{tabular}{lcccccc}
\hline Moorings & $\begin{array}{c}\text { Water Depth } \\
(\mathbf{m})\end{array}$ & Latitude & Longitude & Start & Stop & $\begin{array}{c}\text { Depth of } \\
\text { instrument } \\
(\mathbf{m})\end{array}$ \\
\hline M3 & $190 \mathrm{~m}$ & $35^{\circ} 53.42^{\prime}$ & $05^{\circ} 44.20^{\circ}$ & $21 / 10 / 85$ & $21 / 4 / 86$ & $110 \mathrm{~m}$ \\
& & & & $21 / 10 / 85$ & $21 / 4 / 86$ & $140 \mathrm{~m}$ \\
M7 & & & $21 / 10 / 85$ & $21 / 4 / 86$ & $180 \mathrm{~m}$ \\
& $916 \mathrm{~m}$ & $35^{\circ} 59.98^{\prime}$ & $05^{\circ} 22.75^{\circ}$ & $19 / 10 / 85$ & $27 / 3 / 86$ & $54 \mathrm{~m}$ \\
M8 & & & & $19 / 10 / 85$ & $27 / 3 / 86$ & $193 \mathrm{~m}$ \\
\hline
\end{tabular}

To obtain the barotropic semidiurnal signal at each mooring, the following procedure was followed:

Empirical orthogonal function analysis (EOF) (Kundu et al., 1975; Kundu and Allen, 1976; Candela, 1989; Bruno et al., 1996b) was applied to the original current velocity series to obtain the total barotropic signal. Since there was only one current meter at a depth of 30 metres at M8 (Fig. $1 b$ ) it had to be assumed that the recorded signal was the barotropic one. Results of the EOF at moorings M3 and M7 are shown in Tables $2 a$ and $2 b$, respectively, where mode 1 , showing the same sign in the spatial weights (eigenvectors) for all current meters and approximately constant values with depth, is the most energetic one, and can be understood as a close approximation to the barotropic mode. These results agree with those obtained by Candela (1989) for the tidal barotropic mode (see values in brackets in Table 2).

Table 2

Results of EOF application to the original hourly data of current meters. a) At mooring $M 3$; $b$ ) at mooring $M 7 .{ }^{*}$ means for percentage of variance explained for each mode in each of the current meters. ** means for total percentage of variance explained for each mode. Values obtained by Candela (1989) for mooring M3 are shown between brackets.

a)

\begin{tabular}{|c|c|c|c|c|c|c|c|}
\hline \multirow[t]{2}{*}{ Mode } & \multicolumn{3}{|c|}{ Eigenvectors } & \multicolumn{3}{|c|}{ Variance* } & \multirow{2}{*}{$\begin{array}{l}\text { Var** } \\
\text { Total }\end{array}$} \\
\hline & C3110 & C3140 & C3180 & C3110 & C.3140 & C.3180 & \\
\hline $1^{\circ}$ & $\begin{array}{c}82.0 \\
(92.6)\end{array}$ & $\begin{array}{c}71.2 \\
(83.6)\end{array}$ & $\begin{array}{c}46.5 \\
(55.8)\end{array}$ & 99.6 & 99.7 & 97.4 & 99.31 \\
\hline $2^{\circ}$ & -3.9 & -0.3 & -4.1 & 0.2 & 0.00 & 0.3 & 0.50 \\
\hline $3^{\circ}$ & 2.9 & -4.1 & 1.3 & 0.1 & 0.3 & 0.08 & 0.19 \\
\hline
\end{tabular}

b)

\begin{tabular}{|c|c|c|c|c|c|}
\hline \multirow[t]{2}{*}{ Mode } & \multicolumn{2}{|c|}{ Eigenvectors } & \multicolumn{2}{|c|}{ Variance* } & \multirow{2}{*}{$\begin{array}{l}\text { Var** } \\
\text { Total }\end{array}$} \\
\hline & C754 & C7193 & C754 & C7193 & \\
\hline $\begin{array}{l}1^{\circ} \\
2^{\circ}\end{array}$ & 16.3 & 23.4 & 54.3 & 81.6 & 69.7 \\
\hline $2^{\circ}$ & -15.4 & 11.1 & 45.7 & 18.4 & 30.3 \\
\hline
\end{tabular}

The Fast Fourier Transform filter on the total barotropic signal was applied to the isolate barotropic semidiurnal signal on each mooring. Once this signal was obtained, a least-squares harmonic analysis (Foreman, 1976) was applied to estimate the harmonic constants for the main semidiurnal tidal constituents. These constants are presented in Table 3 for the three selected moorings.

Once the barotropic semidiurnal signal was obtained, the $U_{m}(t)$ and $\phi_{m}(t)$ series were obtained as follows.

A prediction without the $M_{2}$ constituent was generated using the constants of Table 3 and subtracted from the barotropic semidiurnal signal. The resulting signal was thus composed of the $M_{2}$ signal plus the semidiurnal residue, and can be understood as a distorted $M_{2}$ signal which can be characterized by the expression:

$u_{M / 2}^{d}(t)=U_{m}(t) \cos \left[\omega_{M 2} t-\phi_{m}(t)\right]$

where $u_{M 2}^{d}(t)$ is the distorted $M_{2}$ signal and $U_{m}(t)$ and $\phi_{m}(t)$ are the slow variations in time of the amplitude and phase lag of the $M_{2}$ signal. It should be noted that the semidiurnal residue contains not only the distortion effects felt by the $M_{2}$ signal but also those felt by the other semidiurnal constituents. However, considering that the $M_{2}$ constituent accounts over $64 \%$ of the variance contained in the semidiurnal band, the distortion of the total semidiurnal signal can be basically represented the distortion of the $M_{2}$ signal. Hence the signal given in equation (1) is called the distorted $M_{2}$ signal.

Table 3

Harmonic constants estimation of the tidal barotropic semidiurnal signal in the current velocity at the moorings M8, M3 and M7. A is the amplitude in $\mathrm{cm} \mathrm{s}^{-1}$ and $G$ is the Greenwich phase lag in degrees.

\begin{tabular}{lrrrrrrr}
\hline $\begin{array}{l}\text { Component } \begin{array}{c}\text { Period } \\
\text { (hours) }\end{array} \\
\end{array}$ & \multicolumn{2}{l}{ Mooring 8 } & \multicolumn{2}{c}{ Mooring 3 } & \multicolumn{2}{c}{ Mooring 7 } \\
& & A & G & A & G & A & G \\
\hline$\varepsilon_{2}$ & 13.12 & 1.58 & 117.3 & 0.71 & 123.9 & 1.27 & 72.6 \\
$H_{2}$ & 12.87 & 3.29 & 138.5 & 0.33 & 59.8 & 4.10 & 110.7 \\
$N_{2}$ & 12.65 & 14.98 & 134.6 & 17.87 & 120.9 & 6.80 & 129.9 \\
$M_{2}$ & 12.42 & 65.15 & 156.5 & 90.83 & 146.6 & 24.85 & 159.5 \\
$L_{2}$ & 12.19 & 1.37 & 154.3 & 2.46 & 171.3 & 2.67 & 310.9 \\
$S_{2}$ & 11.99 & 22.60 & 185.1 & 30.70 & 170.5 & 12.43 & 177.9 \\
$K_{2}$ & 11.96 & 6.78 & 185.8 & 9.21 & 171.2 & 3.73 & 178.6 \\
$\eta_{2}$ & 11.75 & 0.65 & 97.4 & 0.91 & 18.6 & 0.30 & 331.7 \\
\hline
\end{tabular}

Next, the $U_{m}(t)$ and $\phi_{m}(t)$ scrics were obtained by the application of complex demodulation at the $M_{2}$ frequency to the series $u_{\lambda r}^{d}(t)$ (Korn and Korn, 1986; Garrett et al., 1989; Bruno et al., 1996a; Mañanes, 1996). 
Table 4

Results of EOF application to the subinertial signal of current meters at moorings $M 3, M 8$ and $M 7$. * means for percentage of variance explained for each mode in each of the current meters. ** means for total percentage of variance explained for each mode. Values obtained by Candela (1989) for mooring M3 are shown between brackets.

\begin{tabular}{|c|c|c|c|c|c|c|c|c|c|c|c|}
\hline \multirow[t]{2}{*}{ Mode } & \multicolumn{5}{|c|}{ Eigenvectors } & \multicolumn{5}{|c|}{ Variance* } & \multirow{2}{*}{$\begin{array}{l}\text { Var** } \\
\text { Total }\end{array}$} \\
\hline & $\mathbf{C 3 1 1 0}$ & C3140 & C3180 & C7193 & $\mathbf{C 8 3 0}$ & $\mathbf{C 3 1 1 0}$ & C3140 & $\mathbf{C 3 1 8 0}$ & C7193 & C830 & \\
\hline $1^{\circ}$ & $\begin{array}{c}16.8 \\
(17.3)\end{array}$ & $\begin{array}{c}16.5 \\
(17.4)\end{array}$ & $\begin{array}{c}11.2 \\
(12.0)\end{array}$ & 4.6 & 5.3 & 93.5 & 97.3 & 83.2 & 54.1 & 38.6 & $\begin{array}{c}86.3 \\
(80.0)\end{array}$ \\
\hline $2^{\circ}$ & -2.7 & 1.4 & 4.1 & 1.5 & -5.6 & 2.4 & 0.7 & 11.0 & 6.1 & 43.2 & 7.1 \\
\hline $3^{\circ}$ & 3.3 & -0.3 & -2.4 & -0.8 & -3.7 & 3.6 & 0.0 & 4.0 & 1.9 & 18.2 & 3.7 \\
\hline $4^{\circ}$ & 0.6 & -1.3 & -0.5 & 3.8 & 0.1 & 0.1 & 0.6 & 0.2 & 37.0 & 0.0 & 2.0 \\
\hline $5^{\circ}$ & 1.0 & -1.9 & 1.6 & -0.6 & 0.1 & 0.3 & 1.4 & 1,7 & 0.9 & 0.0 & 0.9 \\
\hline
\end{tabular}

The barotropic subinertial signal was obtained as follows:

The moving average filter $A_{24} A_{24} A_{25}$ (Godin, 1972), which has a cut frequency of 0.033 cycles/hour corresponding to a period of 30 hours, was applied to the original hourly data yielding the subinertial signal at all the current meters.

EOF is applied on the subinertial signal of all current meters in order to seek a common mode characterizing the barotropic subinertial oscillation along the Strait. Current meter C754, located at mooring M7 at a depth of $54 \mathrm{~m}$ (Fig. 1b), was not included in the analysis because of its anomalous behaviour with respect to the other current meters deployed in the Gibraltar Experiment. In this current meter, the subinertial signal accounted for $53 \%$ of the total variance, while the characteristic percentage of the variance explained by the subinertial signal in the others was $6 \%$ (Candela, 1989; Candela et al., 1990). The results of the EOF analysis are presented in Tables 3 and 4, where it should be noted that the spatial weights of mode 1 show the same sign for all the current meters and the spatial weights associated to this mode are nearly uniform with depth at the M3 mooring, which was therefore chosen as the representative barotropic subinertial mode and called $M_{1}(t)$. Results follow those obtained by Candela (1989) and Candela et al. (1989) for barotropic subinertial mode in M3 (see values between brackets in Table 4).

\section{RELATIONSHIP BETWEEN AMPLITUDE AND PHASE VARIATION OF THE $M_{2}$ SIGNAL AND SUBINERTIAL BAROTROPIC MODE}

'The $U_{m}(t), \phi_{m}(t)$ and $M_{1}(t)$ series having been obtained, the relationships between both amplitude and phase variation of the $M_{2}$ signal in the barotropic current velocity, and the barotropic subinertial mode were analyzed for each of the moorings used.

In Figure 2, certain relationships between both pairs of series $\left(M_{1}(t)\right.$ with $U_{m}(t)$ and $\left.\phi_{m}(t)\right)$ can be observed. To look into this relationship a cross-spectral analysis between both pairs of series was performed. Results from these analyses for each mooring are shown in Figures 3-5. From Figures $3-5 a$ and $3-5 b$ it can be seen that in the frequency range where the explained percentage of energy is higher for all series (from 0.0432 to 0.1296 cycles/day), the coherence shows significant values, between 0.5 and 0.8 , implying a significant correlation of the two pairs of series at all moorings. From Figures $3 c$ and $4 c$ and Figures $3 d$ and $4 d$, the phase lag between $M_{1}(t)$ and both $U_{m}(t)$ and $\phi_{m}(t)$ series is a function of the frequency at all moorings, yet in the frequency range where the explained percentage of energy is higher its value is located, in the case of $U_{m}(t)$, between 90 and $180^{\circ}$ for all moorings and, in the case of $\phi_{m}(t)$, between 180 and $270^{\circ}$ at moorings M8 and M3 and close to $360^{\circ}$ at mooring M7. Thus the relationships between the barotropic subinertial mode and both amplitude and phase variation of the $M_{2}$ signal show a greater similarity of behaviour between the moorings at the western side of the Strait (M8 and M3) than between these and the mooring at the eastern side (M7). This can be explained by the different dynamic conditions existing on each side of the Strait.

SEMIDIURNAL RESIDUES IN THE CURRENT VELOCITY ALONG THE STRAIT AS A FUNCTION OF SLOW VARIATIONS IN TIME OF AMPLITUDE AND PHASE OF $M_{2}$ SIGNAL

The semidiurnal residue in the barotropic current velocity is defined as

$u_{r}(t)=u_{M 2}^{d}(t)-U_{M 2} \cos \left(\omega_{M 2} t-\delta_{u M 2}\right)$

where $u_{M 2}^{d}(t)$ is given by equation (1); $U_{M 2}$ and $\delta_{u M 2}$ are the estimated harmonic constants, amplitude and phase, of the $M_{2}$ signal in the current velocity; and $\omega_{M 2}$ is the angular frequency of the $M_{2}$ signal. The $u_{M 2}^{d}(t)$ series in equation (2) can be expressed (Bruno et al., 1996a) as:

$u_{M 2}^{d}(t)=U_{M 2} J_{t} \cos \left(\omega_{M 2} t-\delta_{u M 2} \phi_{t}\right)$

where:

$U_{t}=\frac{U_{m}(t)}{U_{M 2}}$

$\phi_{t}=\frac{\phi_{m}(t)}{\delta_{u M 2}}$

are nondimensional factors which express the proportion of amplitude and phase variations with respect to the harmonic constants for the $M_{2}$ constituent. Developing equation (3) 
Figure 2

1.2 signal amplitude and phase distortion series in current velocity, $U_{n}(t)$ (solid lines) and $\phi_{m}(t)$ (dotted lines) at: a) $M 8$; b) $M 3$; c) $M 7$; d) barotmpic subinerial mode $M_{1}(t)$.

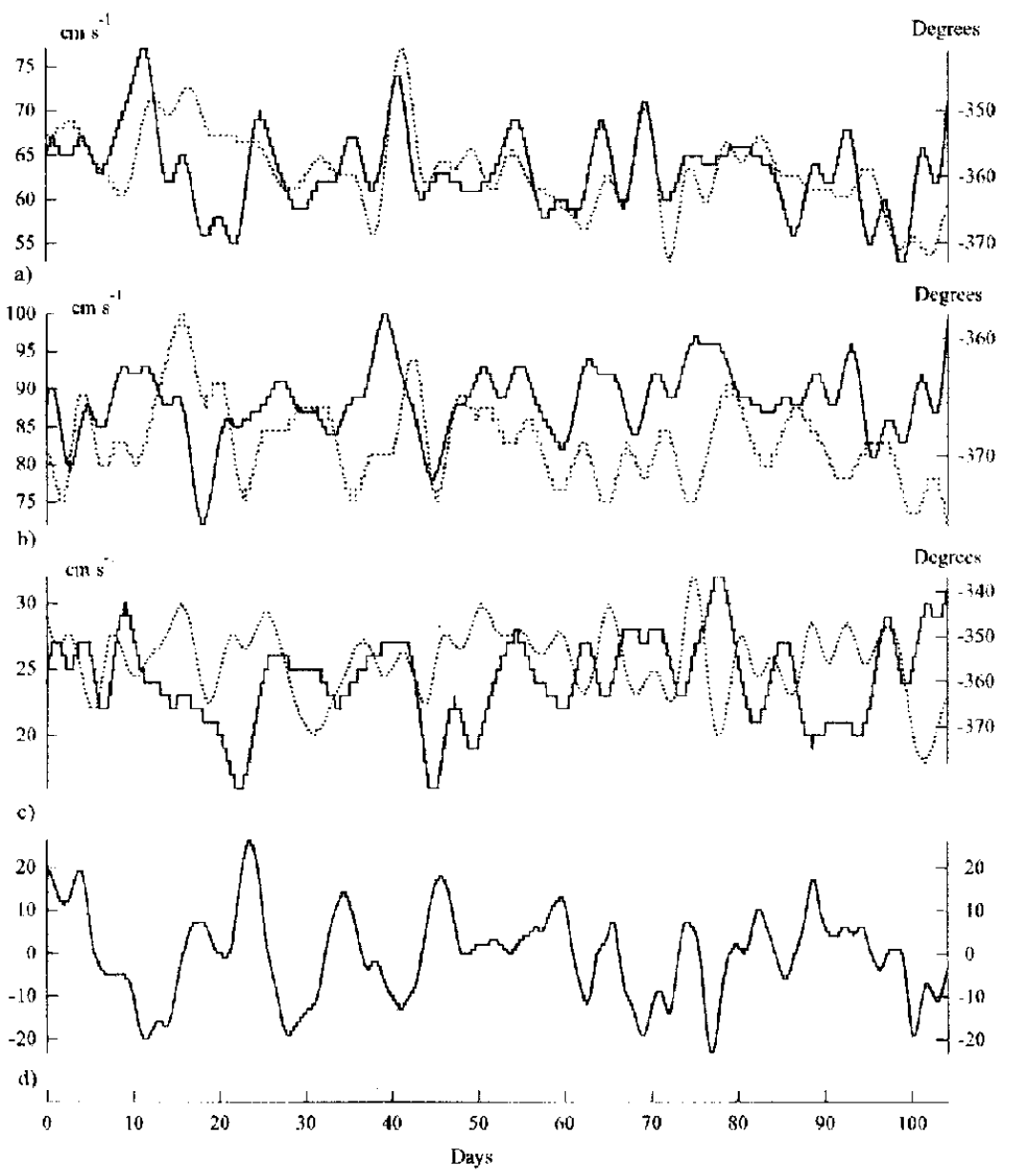

as a function of $U_{t}$ and $\phi_{t}$ by Taylor's series around the undistorted signal ( $U_{t}=1$ and $\left.\phi_{t}=1\right)$ and truncating it in the first order (Bruno et al., 1996a; Mañanes, 1996) results in

$$
\begin{aligned}
& u_{M 2}^{d}(t)=u_{M 2}^{d}(1,1)+\left.\frac{\partial u_{M 2}^{d}}{\partial U_{t}}\right|_{(1,1)}\left(U_{t}-1\right) \\
& +\left.\frac{\partial u_{M 2}^{d}}{\partial \phi_{t}}\right|_{(1,1)}\left(\phi_{t}-1\right)
\end{aligned}
$$

Evaluating the partial derivatives in $U_{t}=1$ and $\phi_{t}=1$, and taking in account that

$u_{M 2}^{t}(t)(1,1)=U_{M 2} \cos \left(\omega_{M 2} t-\delta_{u_{M 2}}\right)$

in equation (4) we obtain

$$
\begin{aligned}
& u_{r}(t)=u_{M 2}^{d}(t)-U_{M 2} \cos \left(\omega_{M 2} t-\delta_{u u_{2}}\right) \\
& \approx U_{M 2} \cos \left(\omega_{M 2} t-\delta_{u_{M 2}}\right)\left(U_{t}-1\right) \\
& +\delta_{u M 2} U_{M 2} \sin \left(\omega_{M 2} t-\delta_{u_{M 2}}\right)\left(\phi_{t}-1\right)
\end{aligned}
$$

The right-hand side of equation (5) can then be considered as an approximation to the semidiumal residue $u_{r}(t)$. Figure 6 shows the residual series estimated from equation (2) (Fig. 6a) and its approximation from equation (5) (Fig. 6b), for mooring M3, during the analyzed period. Also, the differences between the residue and its approximation (Fig. $6 c$ ) are shown. In Table 5 it should be noted that the quotient between the standard deviations of the series in Figure $6 c$ and the series in Figure $6 a$ is 0.0839 , and therefore the approximation to the semidiurnal residue by equation ( 5 ) is quite satisfactory.

From equation (5), the residual variance can be divided into two parts, of which the first one is proportional to the $M_{2}$ signal

$u_{r_{1}}=C_{0} \cos \left(\omega_{M 2} t-\delta_{u M 2}\right)$

Table 5

Standard deviation of semidiurnal residues at moorings $M 8, M 3$ and M7: $\sigma_{3,}$ for the residue from equation (2); $\sigma_{\text {ura }}$ for the residue approximation equation (5); $\sigma_{n+1}$ for the contribution to the semidiurnal residue from the $\mathrm{M}_{2}$ signal amplitude variation; $\sigma_{u} r_{2}$ for the contribution to the semidiumal residue from the $M_{2}$ signal phase variation; und $\sigma_{\mathrm{DI}} \mathrm{I}$ for the difference between the observed and the approximated residue.

\begin{tabular}{lccccc}
\hline Mooring & $\begin{array}{c}\sigma_{\text {ur }} \\
\left(\mathrm{m} \mathrm{s}^{-1}\right)\end{array}$ & $\begin{array}{c}\sigma_{\text {ura }} \\
\left(\mathrm{m} \mathrm{s}^{-1}\right)\end{array}$ & $\begin{array}{c}\sigma_{\text {Dif }} \\
\left(\mathrm{m} \mathrm{s}^{-1}\right)\end{array}$ & $\begin{array}{c}\sigma_{\text {ur1 }} \\
\left(\mathrm{m} \mathrm{s}^{-1}\right)\end{array}$ & $\begin{array}{c}\sigma_{\text {ur2 }} \\
\left(\mathrm{m} \mathrm{s}^{-1}\right)\end{array}$ \\
\hline M8 & 0.076 & 0.078 & 0.0096 & 0.033 & 0.070 \\
M3 & 0.083 & 0.084 & 0.0070 & 0.036 & 0.076 \\
M7 & 0.039 & 0.039 & 0.0067 & 0.023 & 0.031 \\
\hline
\end{tabular}



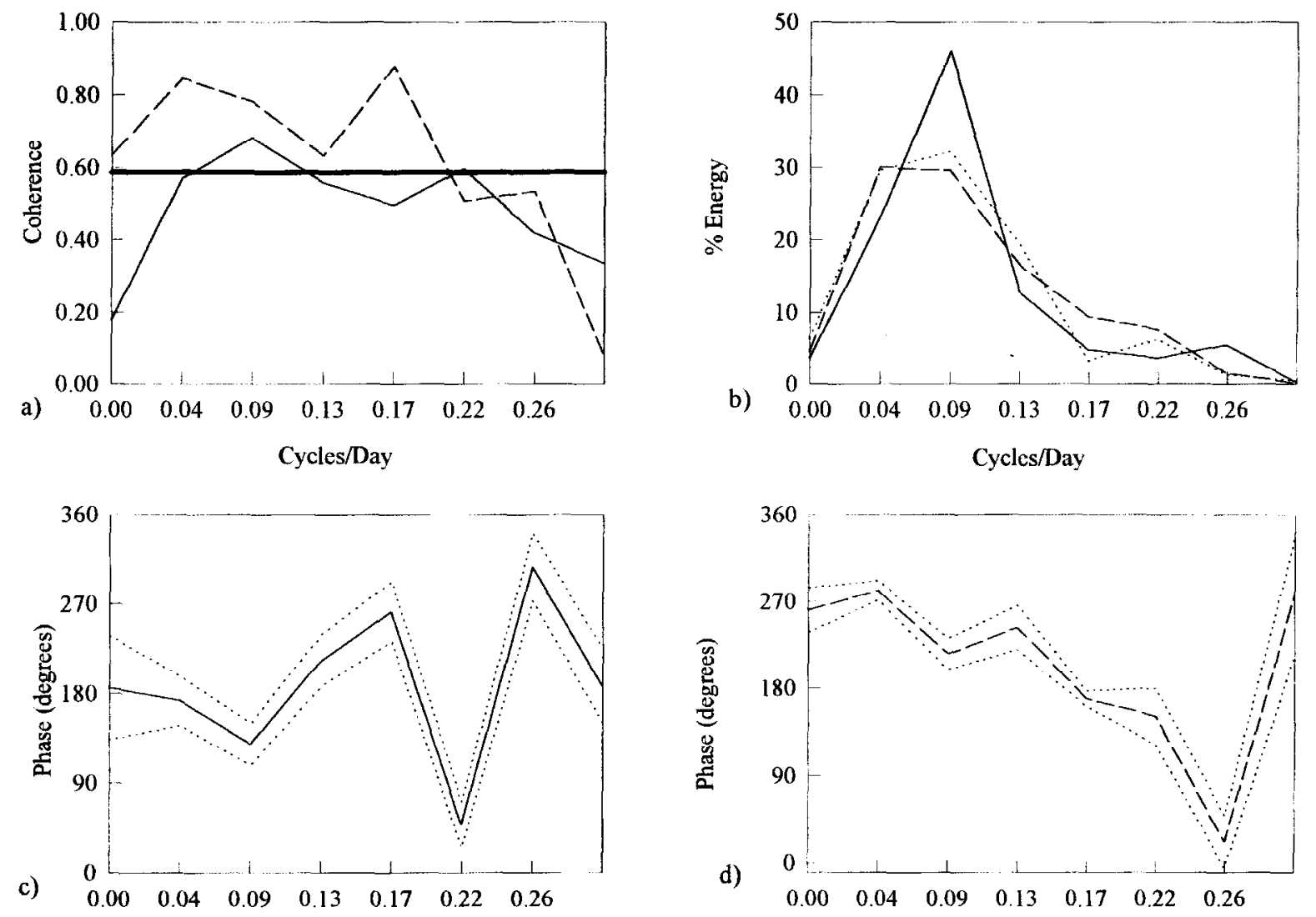

Cycles/Day

Cycles/Day

Figure 3

Results of the cross-spectral analysis between $U_{m}(t), \phi_{m}(t)$ series and $M_{1}(t)$ series at mooring $M 8$. a) coherence diagram $U_{m}(t)$ vs $M_{1}(t)$ and $\phi_{m}(t) v s M_{1}(t)$ (dashed line), horizontal line means for $95 \%$ significant level for coherence in accordance with Box and Jenkins (1970) b) percentage of variance explained for each frequency band $U_{m}(t)$ (solid line) $\phi_{m}(1)$ (dashed line) and $M_{1}(t)($ dotted line); c) phase diagram, cross between $M_{1}(t)$ and $\left.U_{m}(t) d\right)$ phase diagram, cross between $M_{1}(t)$ and $\phi_{m}(t)$. Spectral estimations have been done with nine degrees of freedom and the band width used was $\Delta \omega=0.0432$ cycles/day, confidence intervals for phases were obtained in accordance with Box and Jenkins (1970).

where

$C_{0}=U_{M_{2}}\left(U_{t}-1\right)$

explaining the contribution to semidiurnal residue by the amplitude variations; the second one is proportional to an orthogonal phase-lag signal with respect to the $M_{2}$ one:

$u_{r_{2}}=S_{0} \sin \left(\omega_{M 2} t-\delta_{u_{M 2}}\right)$

where

$S_{0}=\delta_{u M 2} U_{M_{2}}\left(\phi_{t}-1\right)$

for the contribution to semidiurnal residue by the phaselag variations. The different contributions to semidiurnal residue from amplitude and phase-lag variations on the $M_{2}$ signal can thus be evaluated. The $u_{r 1}$ and $u_{r 2}$ series obtained from mooring M3 are shown in Figures $6 d$ and $6 e$, respectively.
The standard deviation of the residues computed from equations (2) and (5) and of the $M_{2}$ signal amplitude and phase variation contributions from equations (6) and (7) are shown in Table 5. The residual signal is higher at mooring M3, like the $M_{2}$ tidal signal (Table 3) showing at mooring $\mathrm{M} 7$ a reciprocal behaviour with the lower values. At mooring M8, values are close to those of mooring M3. Western-side moorings have a contribution of phaselag variation to the residual signal almost double that of the amplitude variation. At mooring M7 the ratio between these contributions is close to unity.

\section{SECOND-ORDER QUASI-ANALYTICAL SOLUTION FOR THE NON-LINEAR INTERACTION BETWEEN TIDAL AND SUBINERTIAL BAROTROPIC OSCILLA- TIONS}

To explain this relationship between amplitude and phase variation of M2 and the barotropic signal in the current 

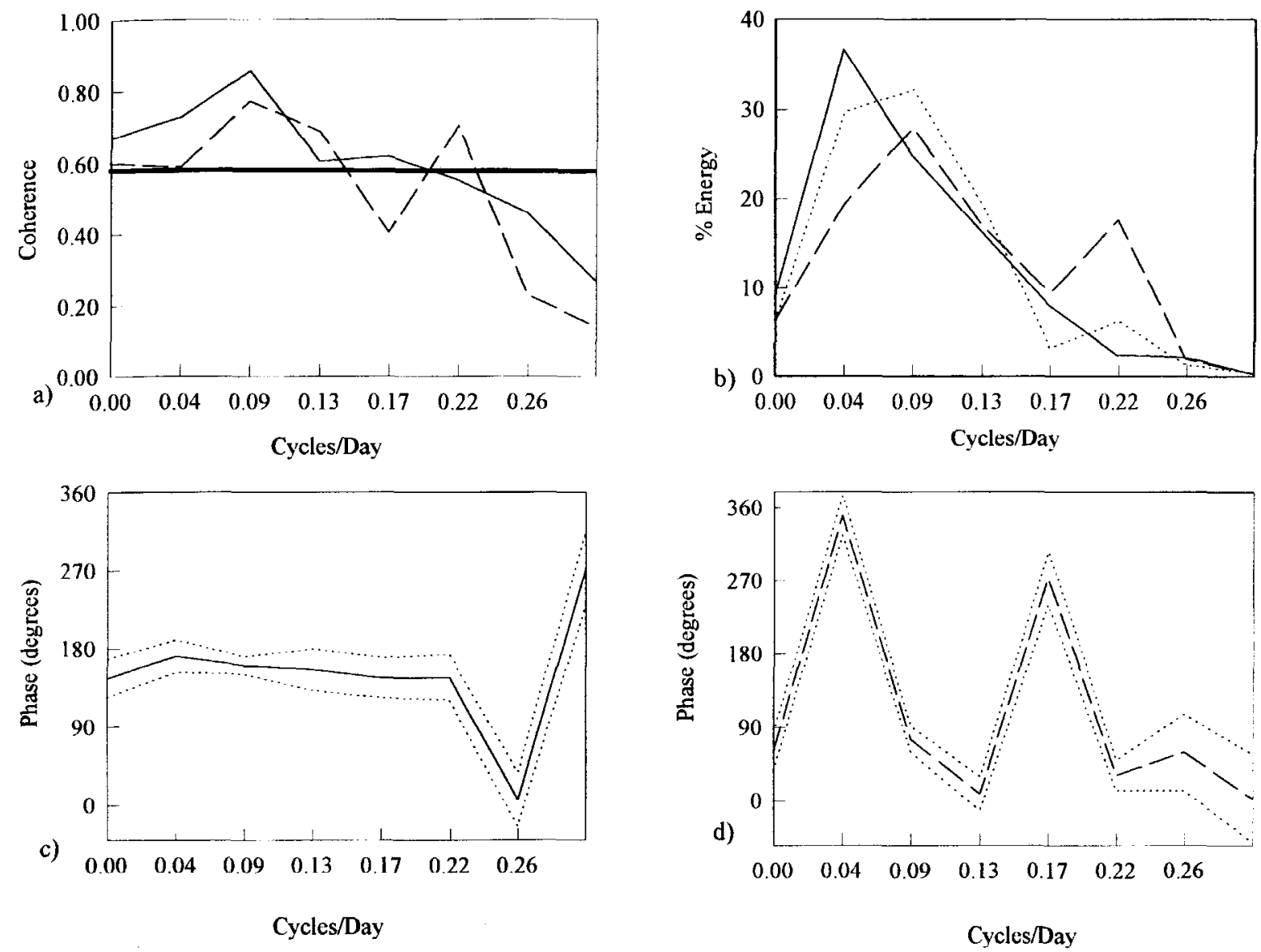

Figure 4

Results of the cross-spectral analysis between $U_{m}(t), \phi_{m}(t)$ series and $M_{1}(t)$ series at mooring $M 8$. a) coherence diagram $U_{m}(t) v s M_{1}(t)$ and $\phi_{m}(t) v s M_{1}(t)$ (dashed line), horizontal line means for 95\% significant level for coherence in accordance with Box and Jenkins (1970) b) percentage of variance explained for each frequency band $U_{m}(t)$ (solid line) $\phi_{m}$ (l) (dashed line) and $M_{1}(t)$ (dotted line); c) phase diagram, cross between $M_{1}(t)$ and $\left.U_{m}(t) d\right)$ phase diagram, cross between $M_{1}(t)$ and $\phi_{m}(t)$. Spectral estimations have been done with nine degrees of freedom and the band width used was $\Delta \omega=0.0432$ cycles/day, confidence intervals for phases were obtained in accordance with Box and Jenkins (1970).

velocity, non-linear interaction between subinertial and semidiurnal signals in the flow will be proposed as the responsible physical mechanism. A second-order solution characterizing this type of non-linear interaction can be established after considering the following:

a) A barotropic 1D flow along the longitudinal $x$ axis of the Strait is assumed. The current velocity in the longitudinal direction is thus characterized by a cross-strait averaged value. Also, sea elevation $\zeta$ is assumed to be constant in the cross-strait direction, and is characterized by a cross-strait averaged value. The Coriolis-term effect on the longitudinal momentum balance is considered to be contained in these averaged values.

b) The bottom friction term is disregarded because of the high cross-strait averaged depth values (Mañanes, 1996).

c) The Strait geometry is treated as an ideal channel of variable rectangular section along the longitudinal coordinate $x, A=b h$ being the area of the section, where $b$ is breadth and $h$ is the effective depth (the cross-strait averaged depth). d) $h+\zeta=h$ is assumed in the mass conservation equation. e) The subinertial oscillation in the flow is assumed to behave as a simple harmonic of frequency $\omega_{1}$.

f) The semidiurnal residue $u_{r}$ arises exclusively from linear interaction between the subinertial and $M_{2}$ signals in the flow.

According to these assumptions, the equations for momentum and mass balances can be expressed as:

$\frac{\partial u}{\partial t}+u \frac{\partial u}{\partial x}=-g \frac{\partial \zeta}{\partial x}$
$\frac{\partial(A u)}{\partial x}=-b \frac{\partial \zeta}{\partial t}$

Next, the variables $\zeta$ and $u$ are expanded using perturbation techniques as a power series of the small parameter $\varepsilon=\zeta / h$

$\zeta=\varepsilon \bar{\zeta}_{f}+\varepsilon^{2} \bar{\zeta}_{s}+\ldots$

$u=\varepsilon \bar{u}_{f}+\varepsilon^{2} \bar{u}_{s}+\ldots$ 

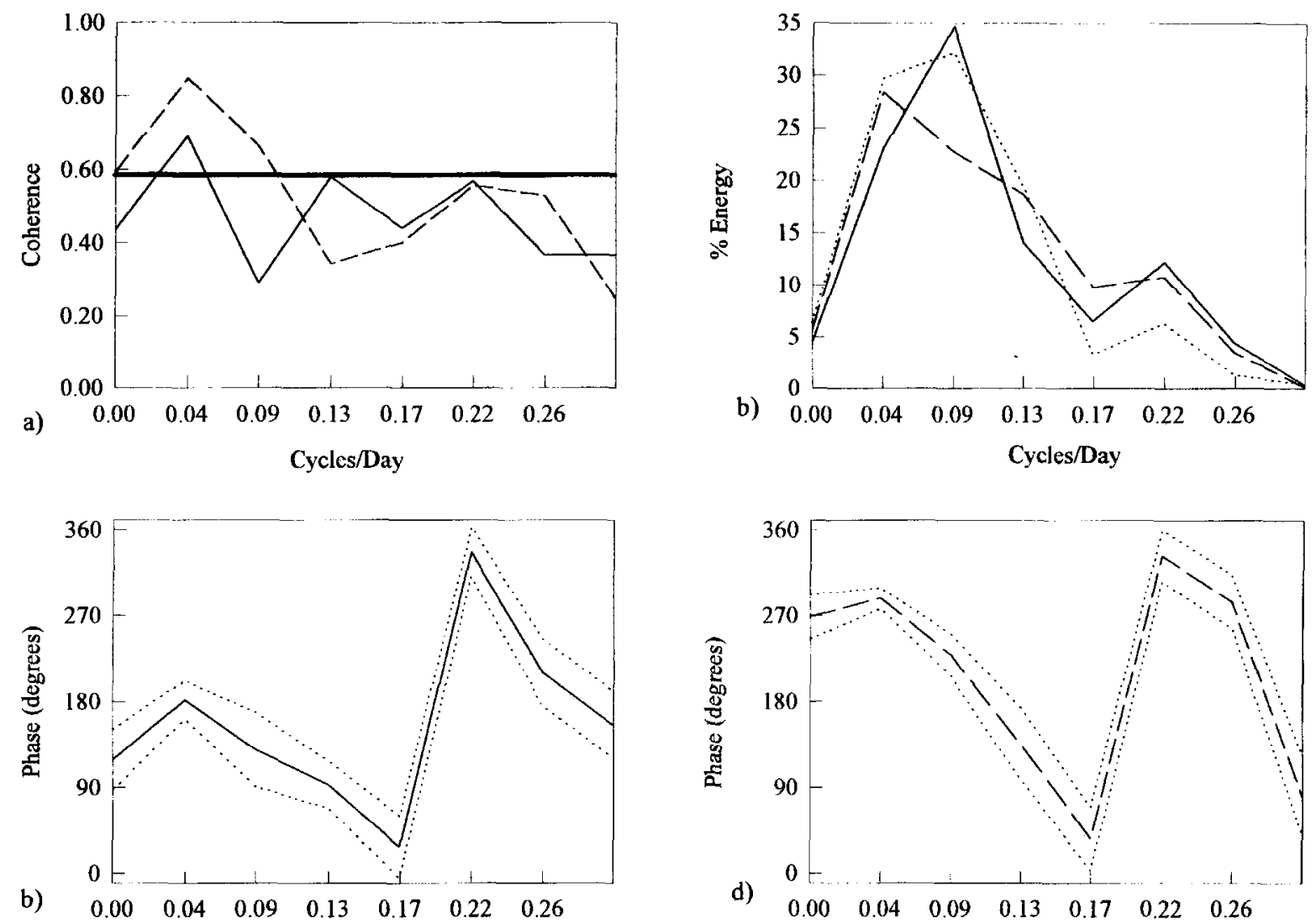

Cycles/Day

Cycles/Day

Figure 5

Results of the cross-spectral analysis between $U_{m}(t), \phi_{m}(t)$ series and $M_{1}(t)$ series at mooring $M 8$. a) coherence diagram $U_{m}(t)$ vs $M_{1}(t)$ and $\phi_{m}(t) v s M_{1}(t)$ (dashed line), horizontal line means for $95 \%$ significant level for coherence in accordance with Box and Jenkins (1970) b) percentage of variance explained for each frequency band $U_{m}(t)$ (solid line) $\phi_{m}$ (1) (dashed line) and $M_{1}(t)$ (dotted line); c) phase diagram, cross between $M_{1}(t)$ and $\left.U_{m}(t) d\right)$ phase diagram, cross between $M_{1}(t)$ and $\phi_{m}(t)$. Spectral estimations have been done with nine degrees of freedom and the band width used was $\Delta \omega-0.0432$ cycles/day, confidence intervals for phases were oblairied in accordance with Box and Jenkins (1970).

of which only the first two terms will be considered, implying that the solution to equations (8) and (9) consists of a first-order solution, $\zeta_{f}=e \bar{\zeta}_{f}$ and $u_{f}=\varepsilon \bar{u}_{f}$; plus a second-order one, $\zeta_{s}=\varepsilon^{2} \bar{\zeta}_{s}$ and $u_{s}=\varepsilon^{2} \bar{u}_{s}$. It will now be assumed that the first-order terms in equations (10) and (11) are composed of

$\zeta_{f}=\zeta_{M 2}+\zeta_{1}$

$u_{f}=u_{M 2}+u_{1}$

i.e. by $M_{2}$ plus a subinertial signal, $u_{1}$ and $\zeta_{1}$.

Taking equations (12) and (13) into equations (8) and (9) and neglecting terms with powers of $\varepsilon$ greater than two, the following system of equations accounting for the effects of non-linear interaction between $u_{M 2}$ and $u_{1}$ variables is obtained

$\frac{\partial u_{s}}{\partial t}+u_{M 2} \frac{\partial u_{1}}{\partial x}+u_{1} \frac{\partial u_{M 2}}{\partial x}=-g \frac{\partial \zeta_{s}}{\partial x}$
$\frac{\partial\left(A u_{s}\right)}{\partial x}--b \frac{\partial \zeta_{s}}{\partial t}$

the first stands for the momentum balance and the second for mass conservation and where the first-order solutions for current velocity associated to the interacting oscillations are characterized as

$u_{M 2}=U_{M 2}(x) \cos \left[\omega_{M 2} t-\delta_{u M 2}(x)\right]$

$u_{1}=U_{1}(x) \cos \left[\omega_{1} t-\delta_{u 1}(x)\right]$

$U_{M 2}(x)$ and $U_{1}(x)$ being the amplitudes of $M_{2}$ and subinertial oscillations and $\delta_{u M 2}(x)$ and $\delta_{u 1}(x)$ their phase lags. All of them, amplitudes and phase lags, are functions of the spatial $x$ co-ordinate.

Substituting the first-order solutions given by equations (16) and (17) into equation (14) and operating with 
Figure 6

Temporal series of the semidiurnal residue in the current velocity at mooring M3. a) semidiurnal residue obtained from equation (2) $u_{r}(1)$; b) semidiurnal residue approximation from equation (5) $u_{r a}(t)$; c) difference between the residues of cases a) and b) $u_{r}(t)-u_{r a}(t)$; d) contribution to the semidiurnal residue from the $\mathrm{M}_{2}$ signal amplitude variation $r_{r 1}(t)$; e) contribution to the semidiurnal residue from the $M_{2}$ signal phase variation $u_{r 2}(t)$. a)

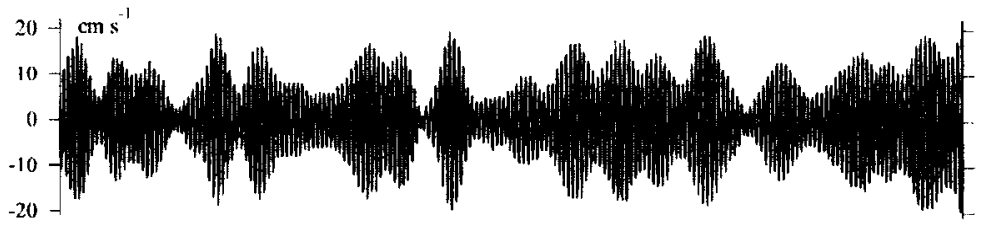

b)

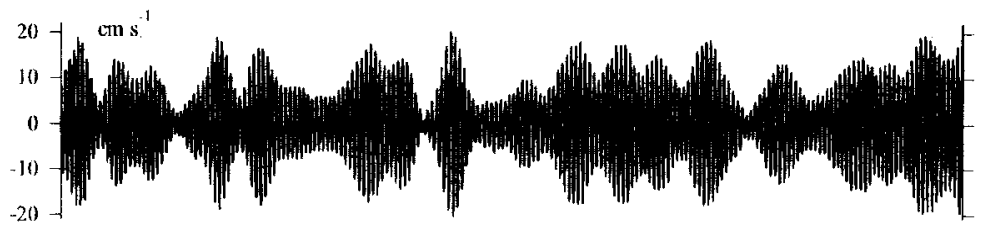

c)

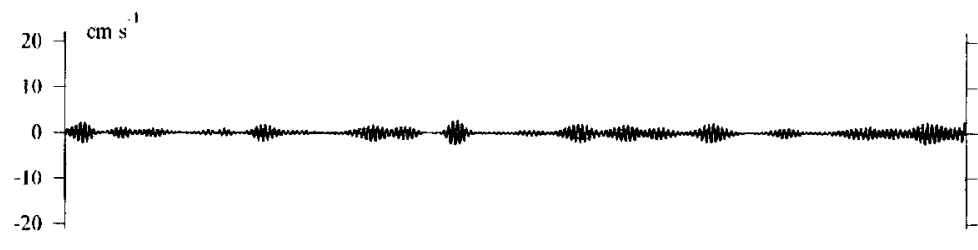

d)
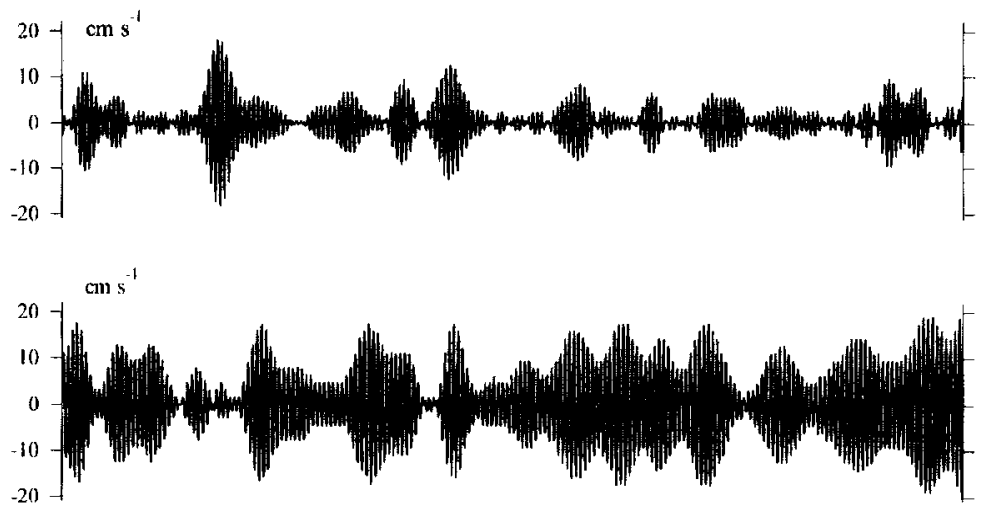

c)

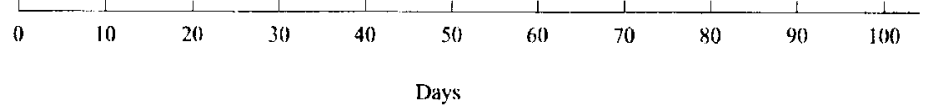

equation (15), the following differential equation for sealevel second-order solution $\zeta_{s}$ is obtained

$$
\begin{aligned}
& \frac{\partial^{2} \zeta_{s}}{\partial x^{2}}-\gamma \frac{\partial \zeta_{s}}{\partial x}-\frac{1}{g h} \frac{\partial^{2} \zeta_{s}}{\partial t^{2}} \\
& =B_{1} \cos \left[\left(\omega_{M 2}-\omega_{1}\right) t-\left(\delta_{u M 2}-\delta_{u_{1}}\right)\right] \\
& +B_{2} \sin \left[\left(\omega_{M 2}-\omega_{1}\right) t-\left(\delta_{u M 2}+\delta_{u_{1}}\right)\right] \\
& +B_{3} \sin \left[\left(\omega_{M 2}-\omega_{1}\right) t-\left(\delta_{u M 2}-\delta_{u_{1}}\right)\right] \\
& +B_{4} \sin \left[\left(\omega_{M 2}+\omega_{1}\right) t-\left(\delta_{u M 2}+\delta_{u_{1}}\right)\right]
\end{aligned}
$$

where the coefficients $B_{i}$ are expressed as:

$$
\begin{aligned}
& B_{1}=\left[\frac{\gamma A}{2}+E+\frac{\gamma D}{2}+H\right] \\
& B_{2}=\left[\frac{\gamma A}{2}+E+\frac{\gamma D}{2}-H\right]
\end{aligned}
$$

$$
\begin{aligned}
& B_{3}=\left[-\frac{\gamma B}{2}-F+\frac{\gamma C}{2}+G\right] \\
& B_{4}=\left[\frac{\gamma B}{2}+F+\frac{\gamma C}{2}+G\right]
\end{aligned}
$$

and

$$
\begin{aligned}
& A=\frac{U_{M 2} U_{1}^{\prime}}{2 g} ; \quad B=\frac{U_{M 2} \delta_{u 1}^{\prime} U_{1}}{2 g} \\
& C=\frac{U_{1} \delta_{u M 2}^{\prime} U_{M 2}}{2 g} ; \quad D=\frac{U_{1} U_{M 2}^{\prime}}{2 g} \\
& E=\frac{U_{M 2}^{\prime} U_{1}}{g} ; \quad F=\frac{U_{M 2}^{\prime} \delta_{u 1} U_{1}}{g} \\
& G=\frac{U_{1}^{\prime} \delta_{u M 2}^{\prime} U_{M 2}}{g} ; \quad H=\frac{\delta_{u 1}^{\prime} U_{1} U_{M 2} \delta_{u M 2}^{\prime}}{g}
\end{aligned}
$$

$\gamma$ parameter is defined as $\gamma=(1 / A)(d A / d x)$ and apostrophe' means derivatives with respect to $x$ coordinate. Thus, coefficients $B_{i}$ are functions of; $U_{M 2}, U_{1}$, $U_{M 2}^{\prime}, U_{1}^{\prime}, \delta_{u M 2}^{\prime}, \delta_{u 1}^{\prime}$ and $\gamma$ parameter. 
If solution $\zeta_{s}$ is evaluated between two sections separated hy a small enough distance, then it can be assumed that:

$B_{i}, U_{M 2}^{\prime}, U_{1}^{\prime}, \delta_{u M L 2}^{\prime}, \delta_{u 1}^{\prime} \gamma=$ constants

that is, the amplitudes, phase lags and area of the sections can be assumed to behave following a linear variation along $x$ axis. After solution $\zeta_{s}$ is obtained under this assumption, its substitution in equation (8) leads to the following second-order solution for current velocity $u_{s}$

$u_{s}=C_{m} \cos \left(\omega_{M 2} t-\delta_{u_{M 2}}\right)+S_{m} \sin \left(\omega_{M 2} t-\delta_{u_{M 2}}\right)$

where

$C_{m}=X_{c} \cos \left(\omega_{1} t-\delta_{u_{1}}+\varphi_{c m}\right)$

$S_{m}=X_{s} \cos \left(\omega_{1} t-\delta_{u_{1}}+\varphi_{s m}\right)$

are time-dependent coefficients, which can be understood as low-frequency harmonics of the same frequency as subinertial oscillation. The constants $X_{c}$ and $X_{s}$ represent the theoretical contribution of the amplitude and phase modulations of the $M_{2}$ signal, respectively, to the amplitude of the non-linearly generated semidiurnal residue. The constants $\varphi_{c}$ and $\varphi_{s}$ represent the phase lag between the modulation of amplitude and phase of the $M_{2}$ signal with respect to subinertial flow. These constants are functions of $\omega_{M 2}, \omega_{1}, U_{M 2}, U_{1}, U_{M 2}^{\prime}, U_{1}^{\prime}, \delta_{u M 2}^{\prime}, \delta_{u 1}^{\prime}$ and $\gamma$ in the following manner:

$$
\begin{aligned}
& X_{c:}=\sqrt{R_{1}^{2}+R_{2}^{2}}, \quad \varphi_{C m}=\arctan \left(-\frac{R_{2}}{R_{1}}\right) \\
& X_{s}=\sqrt{R_{3}^{2}+R_{4}^{2}}, \quad \varphi_{S m}=\arctan \left(-\frac{R_{3}}{R_{4}}\right)
\end{aligned}
$$

where

$$
\begin{aligned}
& R_{1}=\left[-\frac{Z_{3}}{\left(\omega_{M 2}-\omega_{1}\right)}-\frac{Z_{4}}{\left(\omega_{M 2}+\omega_{1}\right)}\right] \\
& R_{2}=\left[\frac{Z_{2}}{\left(\omega_{M 2}+\omega_{1}\right)}-\frac{Z_{1}}{\left(\omega_{M 2}-\omega_{1}\right)}\right] \\
& R_{3}=\left[\frac{Z_{1}}{\left(\omega_{M 2}-\omega_{1}\right)}+\frac{Z_{2}}{\left(\omega_{M 2}+\omega_{1}\right)}\right] \\
& R_{4}=\left[-\frac{Z_{3}}{\left(\omega_{M 2}-\omega_{1}\right)}+\frac{Z_{4}}{\left(\omega_{M 2}+\omega_{1}\right)}\right]
\end{aligned}
$$

and

$$
\begin{aligned}
& Z_{1}=\left(\delta_{u M 2}^{\prime}-\delta_{u 1}^{\prime}\right) g\left(G_{3} \cos \varphi_{1}-G_{1} \sin \varphi_{1}\right)+\frac{A+D}{2} \\
& Z_{2}=\left(\delta_{u M 2}^{\prime}+\delta_{u 1}^{\prime}\right) g \sin \varphi_{1}\left(G_{4}-G_{2}\right)+\frac{A+D}{2} \\
& Z_{3}=-\left(\delta_{u M 2}^{\prime}-\delta_{u 1}^{\prime}\right) g\left(G_{3} \sin \varphi_{1}+G_{1} \cos \varphi_{1}\right)+\frac{C-B}{2} \\
& Z_{4}=\left(\delta_{u M 2}^{\prime}+\delta_{u 1}^{\prime}\right) g \cos \varphi_{2}\left(G_{4}-G_{2}\right)+\frac{B+C}{2}
\end{aligned}
$$

being given $G_{i}$ and $\varphi_{i}$ as

$$
\begin{aligned}
G_{1} & =\frac{B_{1}}{S_{1}} ; \quad G_{2}=\frac{B_{2}}{S_{2}} \\
G_{3} & =\frac{B_{3}}{S_{1}} ; \quad G_{4}=\frac{B_{4}}{S_{2}} \\
\varphi_{1} & =\arctan \left(T_{1}\right) \\
\varphi_{2} & =\arctan \left(T_{2}\right)
\end{aligned}
$$

with

$$
\begin{aligned}
& S_{1}=\sqrt{\begin{array}{l}
{\left[\left(\delta_{u M 2}^{\prime}-\delta_{u 1}^{\prime}\right)^{2}-\frac{\left(\omega_{M 2}-\omega_{1}\right)^{2}}{g h}\right]^{2}} \\
+\gamma^{2}\left(\delta_{u M 2}^{\prime}-\delta_{u 1}^{\prime}\right)^{2}
\end{array}} \\
& S_{2}=\sqrt{\left[\begin{array}{l}
\left.\left(\delta_{u M 2}^{\prime}+\delta_{u 1}^{\prime}\right)^{2}-\frac{\left(\omega_{M 2}+\omega_{1}\right)^{2}}{g h}\right]^{2} \\
+\gamma^{2}\left(\delta_{u M 2}^{\prime}-\delta_{u 1}^{\prime}\right)^{2}
\end{array}\right.} \\
& T_{1}=\frac{\gamma\left(\delta_{u M 2}^{\prime}-\delta_{u 1}^{\prime}\right)}{\left(\delta_{u M 2}^{\prime}-\delta_{u 1}^{\prime}\right)^{2}-\frac{\left(\omega_{M 2}-\omega_{1}\right)^{2}}{g h}} \\
& T_{2}=\frac{\gamma\left(\delta_{u M 2}^{\prime}+\delta_{u 1}^{\prime}\right)}{\left(\delta_{u M 2}^{\prime}+\delta_{u 1}^{\prime}\right)^{2}-\frac{\left(\omega_{M 2}-\omega_{1}\right)^{2}}{g h}}
\end{aligned}
$$

The structure of the solution given by equation (19) is presented in a identical manner to the expression for semidiurnal residue given for equation (5). Therefore, if this semidiurnal residue is the result of the described nonlinear mechanism, $u_{r}=u_{s}$ then the behaviour of the observed time-dependent coefficients $C_{0}$ and $S_{0}$ must be similar to that showed by the theoretical ones $C_{m}$ and $S_{m}$. To compare the observed series $C_{0}$ and $S_{0}$ with the theoretical ones $C_{m}$ and $S_{m}$, the solution given by equation (19) will be evaluated at half-distance between the sections corresponding to moorings M8 and M3. The constants of the solution given by equation (19), $X_{c}, X_{s}, \varphi_{c m}$ and $\varphi_{s m}$, are functions of the quantities $\omega_{M 2}, U_{M 2}, U_{M 2}^{\prime}$, and $\delta_{u M 2}^{\prime}$, associated to the $M_{2}$ signal, and $\omega_{1}, U_{1}, U_{1}^{\prime}$ and $\delta_{u 1}^{\prime}$, associated to the subinertial oscillation. An estimation of the quantities $U_{M 2}, U_{M 2}^{\prime}$, and $\delta_{u M 2}^{\prime}, U_{1}, U_{1}^{\prime}$ can be given if it is supposed that the current-velocity measurements at moorings M3 and M8 are representative for the cross-strait averaged current velocity. As the solution given by equation (19) will be constructed on the above parameters, estimated from the observed current-velocity series, the result will be a quasi-analytical solution.

The parameters associated to the $M_{2}$ signal, of angular frequency $\omega_{M 2}=1.4 \times 10^{-4} \mathrm{rad} s^{-1}$, can be estimated from lable 3, with a distance between moorings M8 and $\mathrm{M} 3$ of $10 \mathrm{~km}$ and assuming a linear variation of current-velocity amplitude between these moorings. Thus the values, $U_{M 2}=0.77 \mathrm{~m} . \mathrm{s}^{-1}$ (the mean value between moorings $\mathrm{M} 3$ and $\mathrm{M} 8$ ) and $U_{M 2}^{\prime}=2.5 \times 10^{-5} \mathrm{~s}^{-1}$ are obtained. Taking into consideration that the phase lag of 
the $M_{2}$ signal in sea elevation varies very slightly in the along-Strait co-ordinate (García, 1986; Candela, 1989) a value $\delta_{u M 2}^{\prime}=0$ is also assumed for the current velocity phase lag.

As more than $90 \%$ of the subinertial current variance, moorings M8 and M3, was explained by the barotropic mode during the subperiod from 3 December 1985 to I 1 January 1986, this was selected to extract the estimates to the associated subinertial signal parameters. A series of depth-averaged values of the subinertial signals from the three current meters of mooring M3 (after removing the mean values of the series) is thus taken to characterize the barotropic subinertial signal in the M3 section. It is further assumed that the M8 subinertial signal is representative for the barotropic subinertial signal in the M8 section.

Once the barotropic subinertial current velocity series have been obtained for the selected subperiod, the parameters associated to the subinertial current oscillation can be estimated via the cross spectral analysis between the subinertial signals at moorings M8 and M3.

From this cross-analysis, we obtain the modulus of the transfer function and phase lag for the three frequencies whose barotropic subinertial variance was higher (see section 2). They are the same for the subperiod used. From these results, see Table 6; $U_{1}^{\prime}$ and $\delta_{u 1}^{\prime}$ can be estimated giving a distance between moorings M8 and M3, $L=10 \mathrm{~km}$, and using the transfer function modulus, $Z\left(\omega_{1}\right)$, and phase lags, $\varphi\left(\omega_{1}\right)$, values:

$$
\begin{aligned}
& U_{1}^{\prime}\left(\omega_{1}\right)=\frac{U_{1 M 3}\left(\omega_{1}\right)-U_{1 M 8}\left(\omega_{1}\right)}{L} \\
& U_{1 M 3}\left(\omega_{1}\right)=Z\left(\omega_{1}\right) U_{1 M 8}\left(\omega_{1}\right) \\
& \delta_{u 1}^{\prime}\left(\omega_{1}\right)=\frac{\varphi\left(\omega_{1}\right)}{L}
\end{aligned}
$$

where $U_{1 M 8}\left(\omega_{1}\right)$ and $U_{1 M 3}\left(\omega_{1}\right)$ are the amplitudes of the subinertial oscillations for each frequency which are obtained by

$$
\begin{aligned}
& U_{1 M 8}\left(\omega_{1}\right)=\left[S_{M 8}\left(\omega_{1}\right) \Delta \omega\right]^{1 / 2} \\
& U_{1 M 3}\left(\omega_{1}\right)=\left[S_{M 3}\left(\omega_{1}\right) \Delta \omega\right]^{1 / 2}
\end{aligned}
$$

\begin{tabular}{|c|c|c|c|c|c|}
\hline $\begin{array}{l}\text { Frequency } \\
\text { (cycle/day) }\end{array}$ & Coherence & $\mathbf{Z}\left(\boldsymbol{\omega}_{1}\right)$ & $\begin{array}{c}\mathrm{U}_{1}\left(\omega_{1}\right) \\
\left(\mathrm{m} \mathrm{s}^{-1}\right)\end{array}$ & $\begin{array}{c}\mathbf{U}_{1}^{\prime}\left(\omega_{1}\right) \\
\left(s^{-1}\right)\end{array}$ & 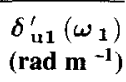 \\
\hline 0.0432 & 0.83 & 1.61 & 0.06 & $3.710^{-6}$ & $-1.610^{-4}$ \\
\hline 0.0864 & 0.95 & 1.60 & 0.11 & $5.310^{6}$ & $-4.710^{-5}$ \\
\hline 0.1296 & 0.97 & 1.53 & 0.05 & $2.210^{-6}$ & $1.010^{-5}$ \\
\hline
\end{tabular}

Table 6

Results of cross-spectral analysis between the subinertial signal at moorings $M 8$ and $M 3$ for the period from 15 November 1985 to 25 December 1985 and estimation of the parameters $U_{1}, U_{1}^{\prime}$ and $\delta_{u 1}^{\prime}$.

where $S_{M 8}\left(\omega_{1}\right)$ and $S_{M 8}\left(\omega_{1}\right)$ are the spectral densities of the subinertial signal at each mooring and $\Delta \omega$ is the band width used in the cross-spectral analysis, $\Delta \omega=0.0432$ cycles/day. Proceeding in this fashion, the values for

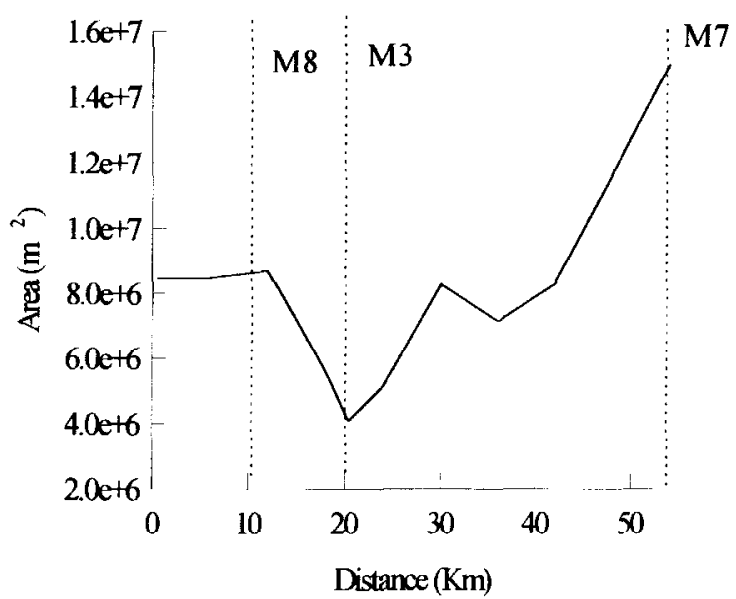

Figure 7

Cross-section area variation along the Strait of Gibraltar. Vertical dotted lines indicate locations of moorings $M 8, M 3$ and $M 7$.

$U_{1}=\left(U_{1 M 8}+U_{1 M 3}\right) / 2, U_{1}^{\prime}$ and $\delta_{u 1}^{\prime}$ presented in the last columns of Table 6 are obtained.

Once the parameters associated to the interacting firstorder oscillations are obtained, and after taking the value of $\gamma=-7.510^{-5}$ (see Figure 7 where the area variations of the ideal rectangular sections along the Strait are shown), and $h=200 \mathrm{~m}$ as the mean depth between moorings M8 and M3, the constants of the solution (eq. (19)) can be evaluated. Since the theoretical solution has a very slight dependence on the frequency $\omega_{1}$ in the range from 0.0432 to 0.1296 cycles/day, a first idea about how this solution is behaving can be achieved by evaluation at a medium frequency $\omega_{1}=0.0864$ cycles/day through different values $U_{1}, U_{1}^{\prime}$ and $\delta_{u 1}^{\prime}$. To perform these computations an averaged value of admittance $\bar{Z}\left(\omega_{1}\right)$ along the three frequencies from Table 6 is taken. Once this value is established, the following relation between the parameters $U_{1}$ and $U_{1}^{\prime}$ is obtained

$U_{1}^{\prime}=\frac{2\left[\bar{Z}\left(\omega_{1}\right)-1\right]}{\left[\bar{Z}\left(\omega_{1}\right)+1\right] L} U_{1}$

Under these conditions, the theoretical solution now depends only on two parameters $U_{1}$ and $\delta_{u 1}^{\prime}$. Thus the theoretical solution is evaluated through the values $U_{1}$ running from 0.01 to $0.40 \mathrm{~m} \mathrm{~s}^{-1}$ each $\Delta U_{1}=0.01 \mathrm{~m} \mathrm{~s}^{-1}$ and through the values for $\delta_{u 1}^{\prime}$ from $-10^{-4} \mathrm{rad}_{11}{ }^{-1}$ each $\Delta \delta_{u 1}^{\prime}=10^{-6} \mathrm{rad} \mathrm{m}^{-1}$. The limits of the $\delta_{u 1}^{\prime}$ values correspond to a phase lag between the two sections, that when they are translated to time, given the value $\omega_{1}=0.0864 \mathrm{cpd}$, they represent a maximum time delay of 1.84 days.

The values for the constants $X_{c}, X_{s}, \varphi_{c}$ and $\varphi_{s}$ resulting from these computations are shown in Figures 8 and 9.

It can be seen that both $X_{c}$ and $X_{s}$ increase when the amplitude of subinertial current velocity $U_{1}$ increases. When $\delta_{u 1}^{\prime}$ is zero, a zero value for $X_{c}$ is obtained while significant values of $X_{s}$ can still be produced. In general, $X_{c}$ has a stronger dependence on $\delta_{u 1}^{\prime}$ than on $X_{s}$. 


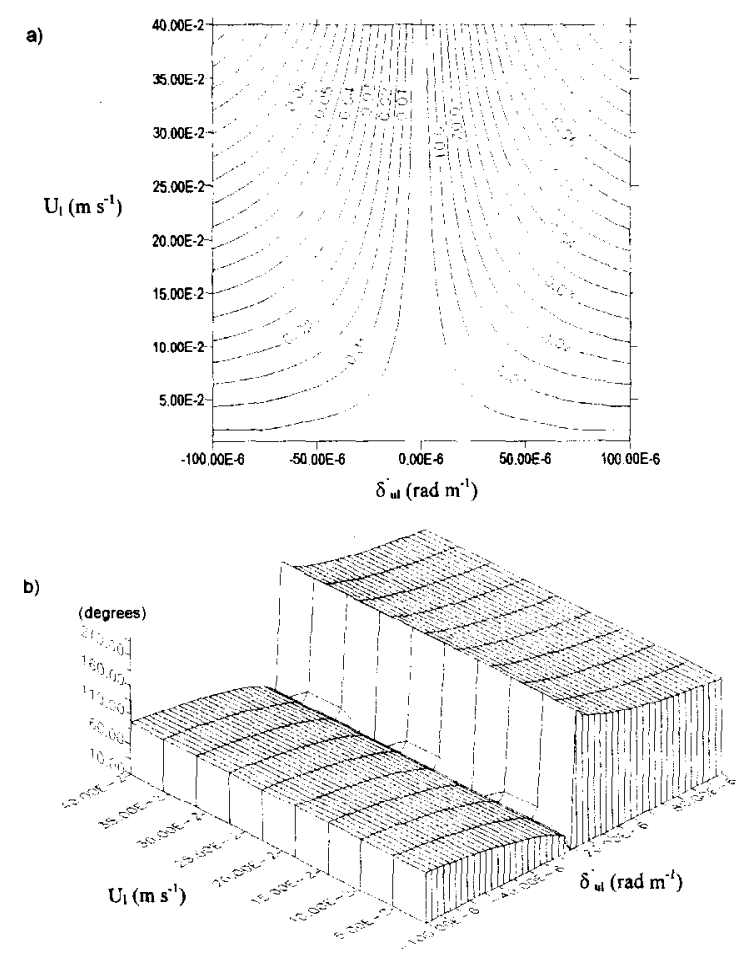

Figure 8

Constants $X_{\mathrm{r}}$ and $\varphi_{\mathrm{rm}}$ of the quasi-analytical solution given by equation (19) through different values of $U_{1}$ and $\delta_{n 1}^{\prime}$ and for a value of $\omega_{1}=0.0864$ cycles/day. a) $X_{c}$ in $\mathrm{m} \mathrm{s}^{-1}$; b) $\varphi_{\mathrm{cm}}$ in degrees.

The phase lags of the variations in amplitude and phase of the $M_{2}$ signal with respect to the subinertial signal $\varphi_{c}$ and $\varphi_{s}$, depend only on $\delta_{u 1}^{\prime}$ and maintain a constant value along the different values of $U_{1}$. For negative $\delta_{u 1}^{\prime}$ values, $\varphi_{c}$ lies between 0 and $100^{\circ}$ and $\varphi_{s}$ between 180 and $260^{\circ}$ while for positive values $\varphi_{c}$ is between 180 and 240 and $\varphi_{s}$ betwecn 0 and $180^{\circ}$. In these results, the variable $\delta_{u 1}^{\prime}$ plays an important role in determining the phase lag of modulations in amplitude and phase of the $M_{2}$ signal with respect to subinertial flow.

\section{COMPARISON BETWEEN THE THEORETICAL SO- LUTION AND THE OBSERVED RESULTS}

In this part, the theoretical results, based on the quasianalytical solution obtained in the previous section, will be compared with the observed results obtained at mooring M3. Using the results of Table 6 (obtained for the subperiod from 3 December 1985 to 11 January 1986) the previous solution is evaluated for each of the frequencies where the major part of the variance of both subinertial oscillation and variations in amplitude and phase of the $M_{2}$ signal was contained. These were: $\omega_{1}=0.0432,0.0864,0.1296$ cycles/day.

In each of these frequencies the behaviour of the observed series $C_{0}$ and $S_{0}$ given in equations (6) and (7) is compared with the theoretical series $C_{m}$ and $S_{m}$ given by equations (20) and (21). In order to perform this comparison, the
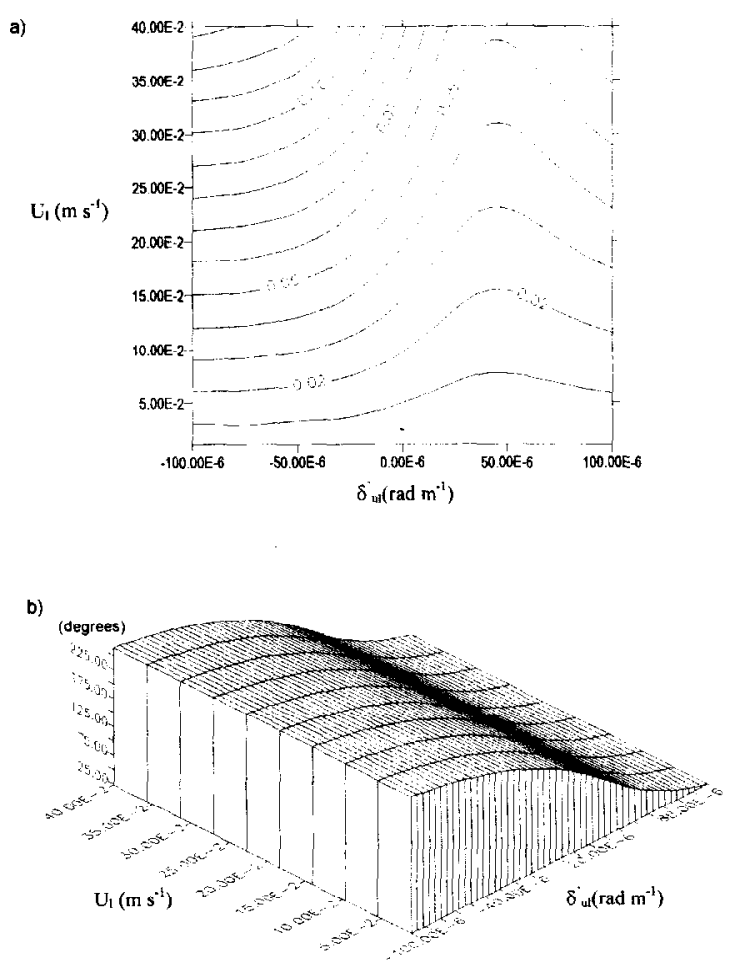

Figure 9

Constants $X_{c}$ and $\varphi_{r \cdot m}$ of the quasi-analytical solution given by equation (19) through different values of $U_{1}$ and $\delta_{u 1}^{\prime}$ and for a value of $\omega_{1}=0.0864$ cycles/day. a) $X_{c}$. in $\mathrm{m} \mathrm{s}^{-1}$; b) $\varphi_{\mathrm{r} \cdot \mathrm{m}}$ in degrees.

variances in each frequency of the observed series are computed as:

$V_{C_{0}}\left(\omega_{1}\right)=S_{C 0}\left(\omega_{1}\right) \Delta \omega$

$V_{S 0}\left(\omega_{1}\right)=S_{S 0}\left(\omega_{1}\right) \Delta \omega$

where $S_{C 0}\left(\omega_{1}\right)$ and $S_{S 0}\left(\omega_{1}\right)$ are the spectral densities of series $C_{0}$ and $S_{0}$, respectively: and $\Delta \omega=0.0018$ cycles/day is the band width used in the spectral estimations. Next, the phase lag of $C_{0}$ and $S_{0}$ series with respect to the subinertial signal $u_{1}$ are computed via cross-spectral analysis and defined as $\varphi_{C 0}$ and $\varphi_{S 0}$, respectively.

On the other hand, the variances of the theoretical series $C_{m}$ and $S_{m}$ in each frequency are defined as

$V_{C m}\left(\omega_{1}\right)=\left[X_{c}\left(\omega_{1}\right)\right]^{2}$

$V_{S m}\left(\omega_{1}\right)=\left[X_{s}\left(\omega_{1}\right)\right]^{2}$

and their phase lags with respect to subinertial signal as in equations (20) and (21).

All of the above quantities are presented in Table 7 for each of the three frequencies, together with the value of coherence among the subinertial flow and the $C_{0}$ and $S_{0}$ series. 
Table 7

Comparison between observed $C_{0}$ and $S_{0}^{\prime}$ (from mooring M3) and theoretical, $C_{m}$ and $S_{m}$, series. Second column shows the coherence values obtained from the spectral cross of series $C_{0}$ and $S_{0}$ with the subinertial oscillation in the current velocity (at mooring M3). a) Values for $C_{0}$ and $C_{m}$. b) Values for $S_{0}$ and $S_{m}$.

a)

\begin{tabular}{lccccc}
\hline $\begin{array}{l}\text { Frequency } \\
\text { (cycles/day) }\end{array}$ & $\begin{array}{c}\text { Cohe- } \\
\text { rence }\end{array}$ & $\begin{array}{c}V_{\mathbf{C o}} \\
\left(\mathbf{c m}^{\mathbf{2}} \mathbf{~ s}^{\mathbf{2}}\right)\end{array}$ & $\begin{array}{c}V_{\mathbf{C m}} \\
\left(\mathbf{c m}^{\mathbf{2}} \mathbf{~ s}^{-\mathbf{2}}\right)\end{array}$ & $\begin{array}{c}\varphi_{\mathrm{Co}} \\
\text { (degrees) }\end{array}$ & $\begin{array}{c}\varphi_{\mathbf{C m}} \\
\text { (degrees) }\end{array}$ \\
\hline 0.0432 & 0.65 & 5.71 & 2.56 & 147 & 108 \\
0.0864 & 0.83 & 12.60 & 2.82 & 121 & 73 \\
0.1296 & 0.61 & 3.61 & 0.06 & 225 & 226 \\
\hline
\end{tabular}

b)

\begin{tabular}{lcrccc}
\hline $\begin{array}{l}\text { Frequency } \\
\text { (cycles/day) }\end{array}$ & $\begin{array}{c}\text { Cohe- } \\
\text { rence }\end{array}$ & $\begin{array}{c}\mathbf{V}_{\text {So }} \\
\left(\mathrm{cm}^{2} \mathrm{~s}^{-2}\right)\end{array}$ & $\begin{array}{c}\mathbf{V}_{\mathrm{Sm}} \\
\left(\mathrm{cm}^{2} \mathrm{~s}^{-2}\right)\end{array}$ & $\begin{array}{c}\varphi \text { so } \\
(\text { degrees })\end{array}$ & $\begin{array}{c}\varphi \mathrm{Sm} \\
\text { (degrees) }\end{array}$ \\
\hline 0.0432 & 0.46 & 3.92 & 3.96 & 270 & 280 \\
0.0864 & 0.93 & 10.00 & 11.00 & 209 & 234 \\
0.1296 & 0.23 & 2.62 & 1.02 & 164 & 178 \\
\hline
\end{tabular}

From Table 7, it can be seen that the theoretical results are in good agreement with the observed ones in those frequencies where the coherence between the subinertial flow and the $C_{0}$ and $S_{0}$ series is higher and where at the same time the major part of the variance is concentrated.

As to the comparison between $C_{m}$ and $C_{0}$ series, their maximum variance is located at the frequency 0.0864 cycles/day, although the values for the observed series are much greater than the theoretical ones. The theoretical and observed values for the phase lag with respect to subinertial flow are agree quite well in all the three frequencies being close to $100^{\circ}$ in the two first and having a value of $226^{\circ}$ in the third one.

Concerning the $S_{m}$ and $S_{0}$ series, their maximum variance is also located at the frequency 0.0864 cycles/day and here the values for the theoretical and observed series are fairly similar, as well as the values of their phase lag with respect to subinertial flow.

The theoretical results seem to be in better agreement with the observed ones in the case of $S_{m}$ and $S_{0}$ al least for the two first frequencies where the coherence between subinertial flow and $S_{0}$ is also more significant.
It should be noted that despite of the strong restrictions under which the quasi-analytical solution has been obtained, it does seem to the able to describe a significant part of the investigated phenomenon. Therefore the variations in amplitude and phase lag of the $M_{2}$ signal in the current velocity can be partially explained by the proposed non-lincar mcchanism, interacting non-linearly with the tidal and subinertial flows through the advective term in the momentum balance equation.

In order to read this quasi-analytical result in a more intuitive physical frame, we can take as an example the $\varphi_{\mathrm{cm}}$ and $\varphi_{\mathrm{cm}}$ values corresponding to $\delta_{u 1}^{\prime}=0$. In this case, from Figures 8 and 9 we have values close to $360^{\circ}$ for $\varphi_{c m}$ and $180^{\circ}$ for $\varphi_{s m}$. The value of $\varphi_{s m}$ means that when the subinertial flow is directed towards the Mediterranean $\left(u_{1}>0\right), S_{m}$, and therefore $\phi_{t}$, decreases with a time ahead in the occurence of the tidal current velocity maximum. When the subinertial flow is towards the Atlantic $\left(u_{1}<0\right)$, the inverse situation with a time delay in the occurence of the tidal current maximum is produced. On the other hand, a $\varphi_{\mathrm{cm}}$ close to $360^{\circ}$ mearls that when $u_{1}>0$ or $u_{1}<0$ the tidal current amplitude increases or decreases.

In terms of tidal propagation through isophase and isoamplitude lines of the tidal current velocity (Mañanes, 1996), the above result could be translated into a displacement of these along the Strait direction (east or west) according to the subinertial flow direction. The larger the subinertial flow, the larger this displacement.

Finally, the authors wish to point out that the results obtained are only referred to the western side of the Strait. Further measurements and analyses are needed to investigate the way in which this non-linear interaction affects the tidal signal on the eastern side.

\section{Acknowledgements}

The authors wish to thank Julio Candela, Antonio RuizCañavate and Juan Rico for their helpful comments on this work, which was supported by CYCIT Project No AMB940591 .

\section{REFERENCES}

Box G.E.P. and G.M. Jenkins (1970). Time series analysis, forecasting and control. Holden day, Inc. San Francisco.

Bruno M.R., R. Mañanes, J.J. Alonso, L. Tejedor (1996a). Meteorological tides and relationship with semidiurnal residues. $S c i$. Mar. 60(4), 451-459.

Bruno M., B. Fraguela, J.J. Alonso, R. Mañanes, A. Ruíz, J. Rico $(1996 b)$. The use of EOF in the analysis of mean sea level. An application to Cadiz. Int. Hydrogr. Rev. 73, 99-107.

Bruno M. (1993). Un análisis de las causas que contribuyen a la distorsión de la señal semidiurna de marea en la costa este de la isla de Gran canaria. Ph. D. Thesis, Universidad de Cádiz.
Bryden H.L., J. Candela, T. Kinder (1994). Exchange through the Strait of Gibraltar. Prog. Oceanogr. 33, 201-248.

Candela J., C.D.. Winant, A. Ruíz (1990). Tides in the Strait of Gibraltar. J. Geophys. Res. 95, 7317-7335.

Candela J., C.D. Wianant, H.L. Bryden (1989). Meteorologically forced subinertial flows through the Strait of Gibraltar. J. Geophys. Res. 94, 12667-12674.

Candela J. (1989). Tidal and subinertial Hows through the Strait of Gibraltar. Ph. D. Thesis, S.O.I., La Jolla, California.

Crépon M. (1965). Influence de la pression atmosphérique sur le niveau moyen de la Méditerranée Occidentale et sur le flux à travers 
le détroit de Gibraltar. Cah. Oceanogr. 1, 15-23.

Foreman M.G.G. (1976). Manual for tidal heights and prediction. Pacific Marine Sciences report 77-10. Inst. Ocean of Sciences, Patrice Bay.

García J.M. (1986). Variabilidad del nivel del mar en el Estrecho de Gibraltar: Marea y oscilaciones residuales. $P h$. $D$. Thesis, Universidad de Málaga.

Garret C., J. Akerly, K. Thompson (1989). Low frequency fluctuations in the Strait of Gibraltar from MEDAPLEX sea level data. J. Phys. Oceanogr. 19, 1682-1696.

Godin G. (1972). The analysis of tides. University of Toronto, Toronto.

Korn G.A. and T.M. Korn (1986). Mathematical handbook for scientists and engineers. Mc Graw-Hill, 1130.

Kundu P.K., J.S. Allen, R.L. Smith (1975). Modal decomposition of the velocity field near the Oregon coast. J. Phys. Oceanogr. 5, 683-704.
Kundu P.K. and J.S. Allen (1976). Some three-dimensional characteristics of low-frequency current fuctuations near the Oregon coast. J. Phys. Oceanogr. 5, 181-200.

Lacombe H. and C. Richez (1982). The regime of Strait of Gibraltar. In Hydrodynamics of semi-enclosed seas, J.C.J. Nihoul Ed., Elscvicr Sci. Publ. Comp., New York, 13-73.

Mañanes R., M. Bruno, J. Rico (1995). Un estudio de las variaciones de corto periodo de la onda $M_{2}$ en el Estrecho de Gibraltar. VII Asemblea Nacional de Geofísica, Sesiion de Oceanografia, 130.

Mañanes R. (1996). Interacción no lineal entre los flujos suhinerciales y mareales asociados al régimen barotrópico en el Estrecho de Gibraltar. Ph. D. Thesis, Universidad de Cádiz.

Pillsbury R.D., D. Barstow, J.S. Butero, C. Millero, B. More, G. Pittock, D.C. Root, J. Simpkims III., R.E. Still, H.L. Bryden (1987). Gibraltar Experiment: current measurements in the Strait of Gibraltar. Oregon State University Technical report 87, 29-284.

Ruíz A. (1994). Flujos barotrópicos de marea en el Estrecho de Gibraltar. Ph. D. Thesis, Universidad de Cádiz. 